\title{
Collembola from Hundidero-Gato Cave in Southern Spain, with the description of a new species of Entomobrya Rondani, I86I (Collembola, Entomobryidae)
}

Javier I. Arbea', Virginia García López², Francisco Javier Soria², Pedro Abellán²

I C/ Ría de Solía 3, ch 39, 39610, Astillero, Spain 2 Laboratorio de Entomología Aplicada, Departamento de Zoologia, Facultad de Biologia. Avda. Reina Mercedes, 6, 41012, Sevilla, Spain

Corresponding author: Javier I. Arbea (jarbeapo@gmail.com)

Academic editor: Lubomír Kováč | Received 21 March 2021 | Accepted 14 April 2021 | Published 19 April 2021

http://zoobank.org/4B29C24B-8715-4620-88E9-B4D0086F98FB

Citation: Arbea JI, López VG, Soria FJ, Abellán P (2021) Collembola from Hundidero-Gato Cave in Southern Spain, with the description of a new species of Entomobrya Rondani, 1861 (Collembola, Entomobryidae). Subterranean Biology 38: 77-90. https://doi.org/10.3897/subtbiol.38.66254

\begin{abstract}
This paper deals with some Collembola from a cave at La Sierra de Grazalema (Málaga). In total, eight species of springtails were found. Two may represent new species but there is insufficient material available to prepare full descriptions (one species in the genus Ceratophysella, one in Hypogastrura), one species (Folsomides cf. ayllonensis) is identified to species, but differences from the nominal species suggest further studies may indicate the Grazalema populations represent a distinct form, and one other is described as new to science, Entomobrya virginiae Arbea, sp. nov. The new species is characterized by no sexual dimorphism in colour pattern, 5 central macrochaetae on Abd II and 4 macrochaetae on Abd III. For the identification and description of the new species, the set of characters proposed by Jordana and Baquero (2005) was used.
\end{abstract}

\section{Keywords}

Arthropoda, biospeleology, Entomobryidae, Entomobrya, taxonomy

\section{Introduction}

The Hundidero-Gato system, within the Subbaetic Mountain range (Southern Spain), is a hydrogeological system composed by more than $10 \mathrm{~km}$ of galleries. This cave, located between the municipalities of Montejaque and Benaoján in the province of Málaga

Copyright Javier l. Arbea et al. This is an open access article distributed under the terms of the Creative Commons Attribution License (CC BY 4.0), which permits unrestricted use, distribution, and reproduction in any medium, provided the original author and source are credited. 
(Andalusia, Spain), has two mouths: the first one is Hundidero, which acts as a sink, and the other one, which is called Gato, where the complex drains. The system harbours a wide variety of subterranean environments, including an old subterranean river course, subterranean lakes, broad chambers and galleries (Guerrero Sánchez 2015).

The information about the subterranean biology in this system is scarce and fragmented (García-López et al. 2020). The first studies were carried out in 1865 by Lucas von Heyden, a German entomologist who wanted to find blind coleopterans. Subsequently, the abbot Henri Breuil, in 1914, could see the presence of warm guano inside the cave but did not capture anyone. Years later, in the 1970s, some specific surveys were carried out by certain speleological groups, such as the GE Telefónica of Madrid, GEOS of Sevilla and the E.R.E from C.E.C. from Barcelona, among others. In 1978, a Dutch speleological group described the spider Iberoneta nasewoa Deeleman-Reinhold, 1984, the aquatic amphipod Pseudoniphargus stockin Notenboom, 1987, and the gastropod Iberhoratia gatoa (Boeters, 1980) (Boeters 1980; Deeleman-Reinhold 1984; Notenboom 1987). Despite the interest of many researchers throughout decades, the deepest and most extended studies did not begin until March of 2016 (Hernando and García-López 2016), which revealed a new endemic species, the troglobitic staphylinid Phloeocharis manu Hernando \& García-López, 2016. More recently, twelve spider species have been recorded for this cave, which belong to nine families: Agelenidae, Araneidae, Dysderidae, Hahniidae, Linyphiidae, Liocranidae, Segestriiadae, Tetragnathidae and Uloboridae) (Barrientos et al. 2019).

There are few references on the cave-dwelling Collembola in the Subbaetic System. Only nine species have been recorded in some caves from Sierra de las Nieves, Sierra de Almijara and Sierra de Tejeda (Arbea and Baena 2003; Arbea et al. 2011; Arbea 2012): Ceratophysella engadinensis (Gisin, 1949), Deuteraphorura cebennaria (Gisin, 1956), Onychiurus gevorum Arbea, 2012, Entomobrya pazaristei Denis, 1937, Lepidocyrtus flexicollis Gisin, 1965, Pseudosinella infrequens Gisin \& Gama, 1969, Pseudisotoma monochaeta (Kos, 1942), Heteromurus nitidus (Templeton, 1835) and Troglopedetes absoloni Bonet, 1931. This is the first study in which a cave from the Sierra de Grazalema have been sampled for Collembola capture. The biospeleological work has been developed in the Hundidero-Gato system. A total of 597 specimens have been captured, belonging to 8 different species. Among them there is one new species, belonging to the genus Entomobrya.

\section{Material and methods}

\section{Cave description}

The Hundidero-Gato system is located in the northeast extreme of Sierra de Líbar, within the mountain range of Ronda, in the northwest of the province of Málaga. In this cave we can find three characteristic types of karstification: the first floor corresponds to a first stage, while the lower floor is always flooded; the middle floor is the most relevant as it corresponds with the speleological trek and it is the most developed. 
Due to the extension of the system, we have limited the study area to the most accessible part at the entrance. The coordinates of Hundidero are $36^{\circ} 43^{\prime} 39^{\prime \prime} \mathrm{N}, 5^{\circ} 14^{\prime} 19^{\prime \prime} \mathrm{W}$, about $558 \mathrm{~m}$ above the sea level. The entrance of the cave has a width of $10 \mathrm{~m}$ and a height of approximately $60 \mathrm{~m}$, and $400 \mathrm{~m}$ of depth accessible on foot.

\section{Sampling}

We used baited pitfall traps to collect invertebrates, which were placed in some areas of the cave that were susceptible to harbor fauna. For the pitfall traps we used clinical analysis cans (volume $150 \mathrm{ml}$ ), which were buried and filled with a modification of Turquin's liquid (Domingo-Quero and Alonso-Zarazaga 2010). The traps were baited with Majorcan sausage (cured sausage from Balearic Islands made with pork, paprika, salt and other spices) as attractant (Belda-García et al. 2014). All collected specimens were preserved in $70 \%$ ethanol.

Two areas were sampled: the entrance to the cave, which covers about $400 \mathrm{~m}$ from the mouth to the first lake, and the area called gallery, a ledge located after about $20 \mathrm{~m}$ from the lake, about $20 \mathrm{~m}$ in the vertical of the wall, corresponding to the deepest area that was sampled. In total, sixteen pitfall traps were placed: four in semi-darkness (twilight) and four in total darkness in the entrance area; and five traps in soil with guano and three in soil without guano in gallery. The sampling was carried out in 2016 (both the entrance and gallery) and 2018 (only the entrance), and the traps were placed in the dates that the Natural Park of Sierra the Grazallema allowed us. The traps were in the cave for one week. The entry seasons established by the Park was governed by the activity of the bats, allowing us access from mid-March to mid-April and later from mid-August to mid-November, in order to not disturb the breeding and wintering periods of the bats.

\section{Preparation and analysis}

Some specimens were cleared in Nesbitt's fluid and were mounted in Hoyer's medium for compound microscope observation in phase constrast. Figures were drawn with a camera lucida.

\section{Terminology}

Chaetotaxy schemes in Entomobrya follow Szeptycki (1979), Jordana and Baquero (2005) and Jordana (2012). Symbols used in dorsal chaetotaxy schemes are: open circle in the figures stands for the presence of large mesochaetae or macrochaetae that could be absent in male and juvenile specimens but present in females, closed circle stands for macrochaetae that are always present, black chaetae-like drawings to sensilla, large black circles with a cross line to pseudopores, long chaetae to bothriotricha.

Abbreviations used: Abd = abdominal segment; Ant = antennal segment; as = sensilla $; \mathrm{mc}=\operatorname{mesochaeta}(\mathrm{e}) ; \mathrm{Mc}=\operatorname{macrochaeta}(\mathrm{e}) ; \mathrm{psp}=$ pseudopore$; \mathrm{Th}=$ thoracic segment; $\mathbf{M N C N}=$ National Museum of Natural Sciences at Madrid, Spain; MZUN = Museum of Zoology, University of Navarra, Spain. 


\section{Results}

Family Hypogastruridae Börner, 1906

\section{Ceratophysella sp.}

Material studied. Cueva del Gato, twilight zone, 27-III-2016, 1 q

The single individual collected apparently represents an undescribed species similar to $C$. norensis Cassagnau, 1965, characterized by A-type of chaetotaxy ( $\mathrm{p} 1$ chaeta shorter than p 2 chaeta on Abd IV), dens with 6 chaetae, the basal chaeta more than twice as long as the others, retinaculum with $4+4$ teeth, tibiotarsi with one pointed tenent hair, claw with one internal tooth and two lateral teeth, filament of empodium $2 / 3$ as long as the inner edge of claw, Ant IV with trilobed apical bulb and 7 thin sensilla, slender anal spines 1.5 times the long of the claws and $1.8 \mathrm{~mm}$ length. The species is dark blue and does not show characters typically present in cave-adapted species.

Additional material is needed to confirm the identity of the species.

\section{Hypogastrura sp.}

Material studied. Cueva del Gato, twilight zone, 27-III-2016, 1 juv.

The single individual collected appears to represent a new species similar to $H$. vernalis (Carl, 1901), characterized by tibiotarsi with one slightly knobbed tenent hair, empodium with broad basal lamella, dorso-lateral parts of Th II-III with m6 chaeta, Ant IV with trilobed apical bulb and 7 sensillae, dens with 6-7 chaetae, 2.7 times as long as mucro, PAO nearly the same size as an ommatidium, anal spines minute, on high papillae, coarse body granulation (8 granules between the 11 chaetae of Abd V) and $1 \mathrm{~mm}$ length. The species is grey-blue and does not show characters typically present in cave adapted species.

Additional material is needed to confirm the identity of the species.

\section{Mesogastrura ojcoviensis (Stach, 1919)}

New Sierra de Grazalema (Málaga) record.

Material studied. Cueva del Gato, twilight zone, 27-III-2016, 16 ex; dark zone, 14IV-2016, 1 ex, 13-XI-2016, 2 ex, 4-X-2018, 25 ex; cave galleries, 14-IV-2016, 1 ex, 30-IX-2016, 1 ex.

Edaphic and troglophilous, guanophilous species. This is a common European species in the caves of the Iberian Peninsula (Spain and Portugal) and the Balearic Islands (Jordana et al. 1997). 


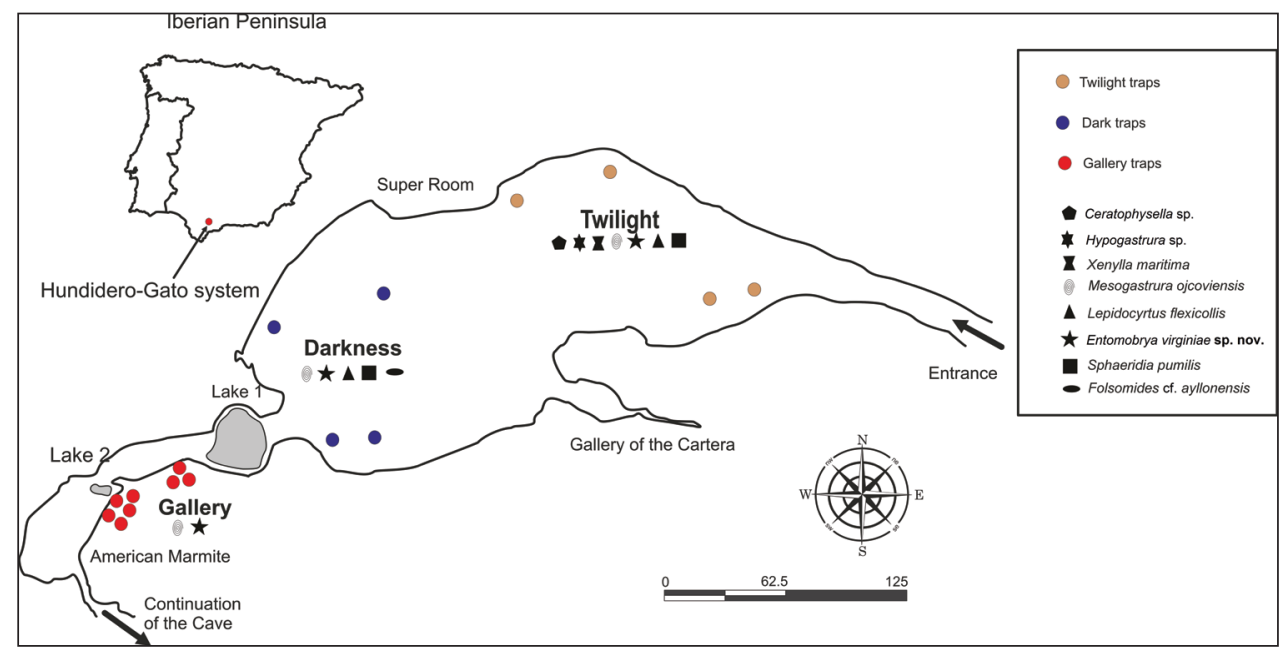

Figure I. Topography of Hundidero-Gato system and locations where the Collembola were sampled. Modified from Guerrero Sánchez (2015). In brown, the twilight pitfall traps, in blue, the darkness pitfall traps and in red, gallery traps (five on guano and three on ground without guano). The different species that appear in each area are represented with their own symbol in the legend.

\section{Xenylla maritima Tullberg, 1869}

New Sierra de Grazalema (Málaga) record.

Material studied. Cueva del Gato, twilight zone, 27-III-2016, 3 ex, 16-VIII-2018, 1 ex.

This is a cosmopolitan species known to occur in dry habitats, surface leaf litter or lichens on rocks (Thibaud et al. 2004). May appear in the mesovoid shallow substratum or in caves accidentally.

\section{Family Isotomidae Schäffer, I896}

\section{Folsomides cf. ayllonensis Simón \& Luciáñez, 1990}

New Sierra de Grazalema (Málaga) record.

Material studied. Cueva del Gato, dark zone, 30-IX-2016, 1 ex.

The species lacks pigment, but has $5+5$ eyes. The juvenile $(0.5 \mathrm{~mm})$ examined differ from F. ayllonensis, as original description (Simón and Luciáñez 1990) and notes made by Fjellberg (1993), in having an oval postantennal organ, 1.7-1.8 as long as omma ( $>2$ in $F$. ayllonensis), and in having three posterior chaetae on dens (two in F. ayllonensis). 


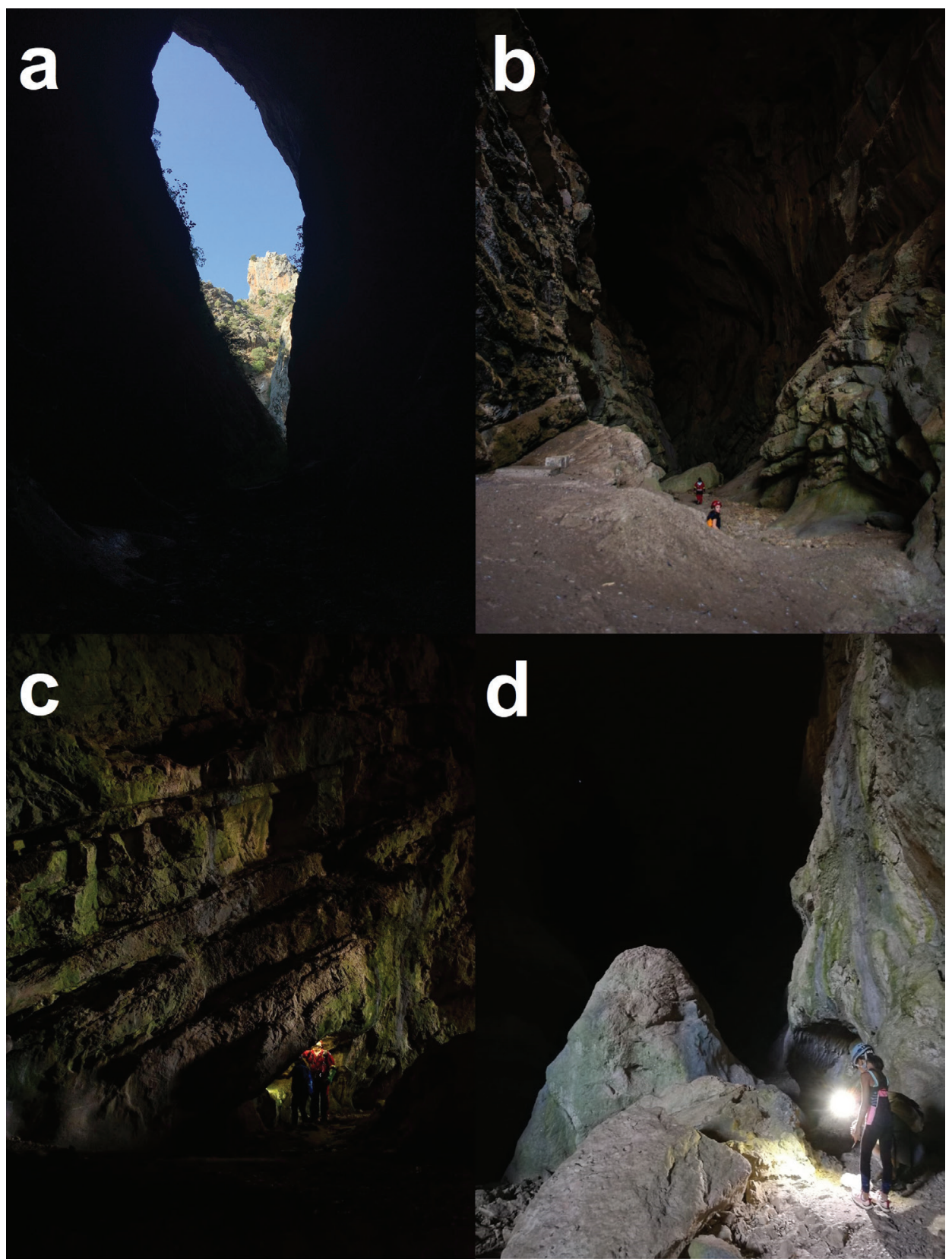

Figure 2. Hundidero Gato cave $\mathbf{a}$ exterior view from Hundidero $\mathbf{b}$ Hundidero entrance $\mathbf{c}, \mathbf{d}$ dark zone, making direct captures (Photo by Miguel de Felipe).

The physical distance $(\approx 690 \mathrm{~km})$ and morphological differences between the Grazalema and Ayllón populations suggest they may represent distinct species, but additional material from Sierra de Grazalema will be needed to determine if the morphological differences noted here are fixed. 


\section{Family Entomobryidae Schäffer, I 896}

\section{Entomobrya virginiae Arbea, sp. nov.}

http://zoobank.org/0391BA36-456A-44BE-84BA-5C82C944D00A

Figs 3-15, Tables 1, 2

Type locality. Sistema Hundidero-Gato, Benaoján-Montejaque, Málaga (Sierra de Grazalema Natural Park, Spain), 3643'39"N, 5¹4'19"W, 558 m a.s.l.

Type material. Holotype female on slide, Sistema Hundidero-Gato, BenaojánMontejaque, Málaga (Spain), dark zone, 23-VIII-2018, leg. Virginia García López; 80 paratypes, same data as holotype: 12 females, 4 males and 4 juveniles on slide (11 from twilight and 9 from dark zone) and 60 ex. in a tube with ethyl alcohol (20 from twilight and 40 from dark zone). Deposited in MNCN (holotype and paratypes in slides) and MZUN (paratypes in alcohol).

Etymology. The name is dedicated to Virginia García López, who captured the specimens.

Description. Body length $1.80 \mathrm{~mm}$, excluding antennae (mean 16 ex., Table 1). Without dimorphism in colour; ground colour white or very light blue, with blue pigment on lateral body (all segments), dorsolateral segments Th II to Abd V, as two not complete stripes wider on posterior tergites, a central patch on Abd III with a truncated cone shape, other central patches on Abd I-II, and transversal bands on posterior tergites Th II-Abd III in many specimens; head with pigment on posterior lateral eyes and a dorsal V-shaped patch; on legs, pigment on distal femur and lateral tibiotarsus; antennae with pigment on Ant I tip and whole Ant II-IV (Fig. 3). Simplified Mc formula (Jordana and Baquero 2005) H1-H2-H3-H4-H5/T1-T2/A1-A2/A3-A4-A5/ A6-A7-A8-A9-A10 in adult females: 3-2-0-3-2/2-4/2-3/1-2-1/0-4-3-2-2.

Head. Eight eyes, GH smaller than EF. Antennae length $1.08 \mathrm{~mm}, 3.13$ times the length of the head ( $\mathrm{n}=16$, Table 1$)$; Ant IV with apical vesicle simple (Fig. 10) (slightly bilobed in some specimens); relative length of Ant I/II/III/IV = 1/2.38/2.42/2.43 (Table 1). Labrum with 4/5,5,4 chaetae; prelabral chaetae ciliated, and labral chaetae smooth. The labium has MR*ELL ciliated Mc; $\mathrm{R}^{*}$ half as long as $\mathrm{M}$; the remaining labial Mc are smooth. The maxillary palp has three sublobal chaetae. The papilla E has a lateral process reaching the end of the papilla (Fig. 9). In the dorsal head chaetotaxy (Fig. 4), the H1 area has three Mc: An2, An3e1 and An3, and the H2 area with two Mc: A5 and A6 (sometimes absent or as mc in male and juvenile specimens); Mc series M with M1-M4; the H3 area without Mc S'0; the H4 area with S1, S3 and S4 Mc, and the H5 area with Ps2 and Ps5 Mc. There are four chaetae on the ocular well: $\mathrm{p}, \mathrm{q}, \mathrm{r}$ and $\mathrm{s}$.

Thorax (Fig. 5). Th II has two Mc: $\mathrm{m} 1$ and $\mathrm{m} 2 \mathrm{i}$, on the $\mathrm{T} 1$ area; the T2 area has four Mc: m4, m4i, a5 and a5' (sometimes absent or as mc in male of juvenile specimens). Th III has complete basal chaetotaxy: a1-a7, p1-p6, m6-m7.

Abdomen (Figs 6,7). The Abd II has two Mc on area A1: a2 and a3 (sometimes absent or as mc in male or juvenile specimens) and three Mc on area A2: $\mathrm{m} 3, \mathrm{~m} 3 \mathrm{ep}$ and m3e. Abd. III has 1, 2 and $1 \mathrm{Mc}$ on areas A3, A4 and A5, respectively: a1, a2, a3 (some- 


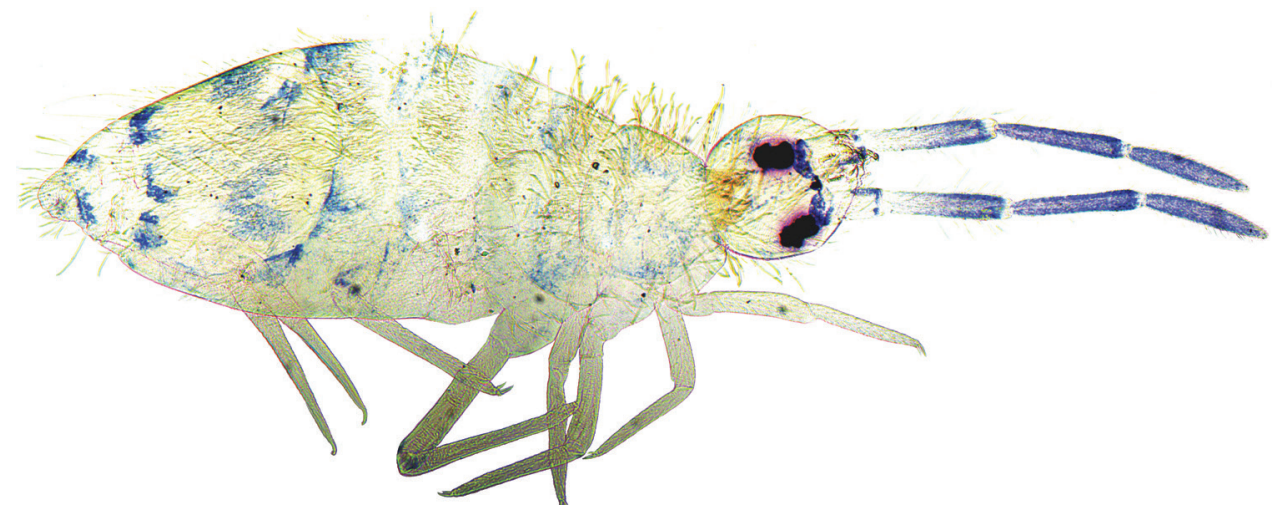

Figure 3. Entomobrya virginiae Arbea, sp. nov. Habitus.
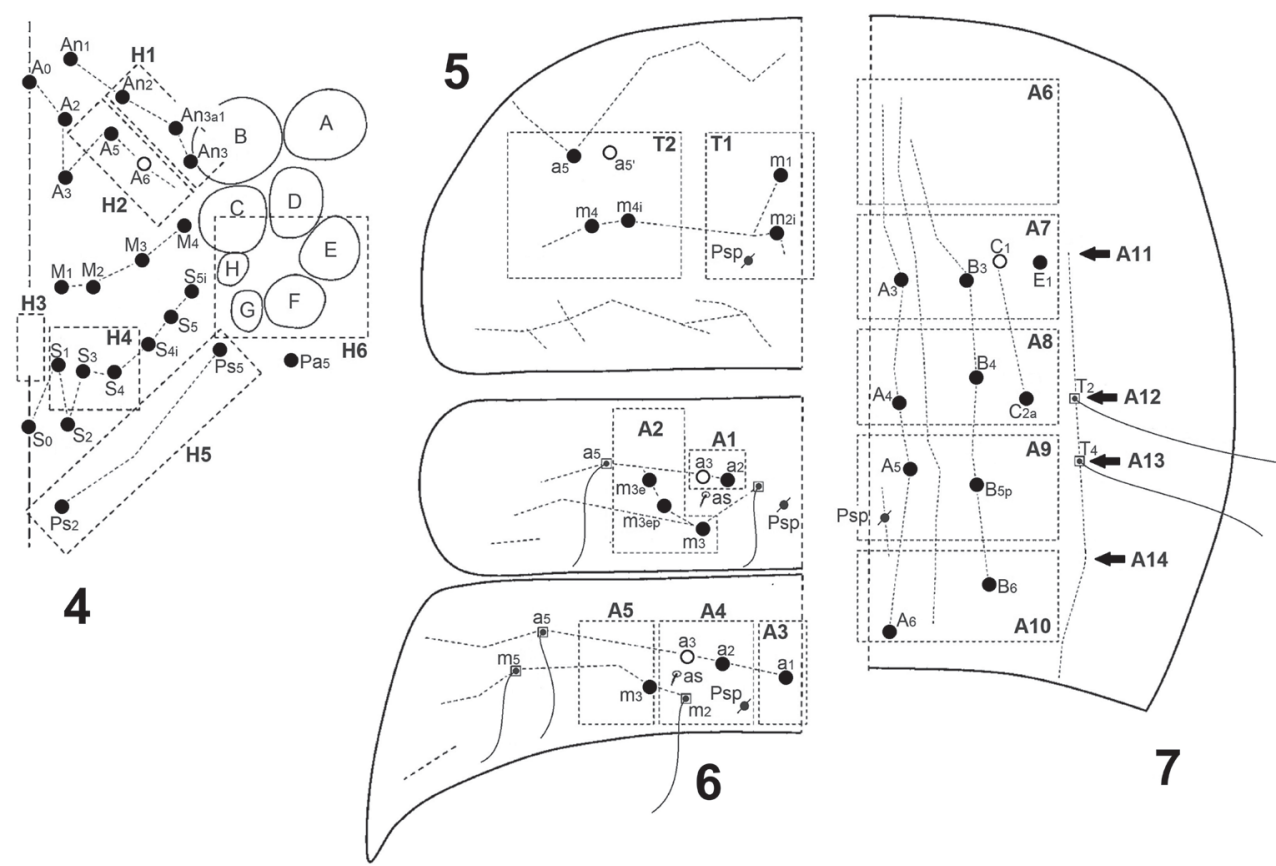

Figures 4-7. Entomobrya virginiae Arbea, sp. nov. 4 head chaetotaxy 5 Th II chaetotaxy 6 Abd II-III chaetotaxy 7 Abd IV chaetotaxy. Symbols: open circle = Mc that could be absent in male and juvenile specimens but present in females; closed circle $=$ Mc that are always present; black chaetae-like $=$ sensilla; black circles with a cross line $=$ pseudopores; long chaetae $=$ bothriotricha .

times absent or as mc in male or juvenile specimens) and $\mathrm{m} 3$. Abd. IV with 11+11 central Mc: A3-A6, B3-B6, C1 (sometimes absent), C2a and E1 (Fig. 7). The trichobothria on Abd IV at the levels T2 and T4. Length ratio of Abd IV/III = $3.78(\mathrm{n}=16$, Table 1). Length of manubrium and dens 0.35 and $0.43 \mathrm{~mm}$, respectively $(\mathrm{n}=16$, Table 1$)$. Manubrial plate with four chaetae and two pseudopores (Fig. 13). Mucro with teeth similar in size, mucronal spine reaching tip of subapical tooth (Fig. 12). 

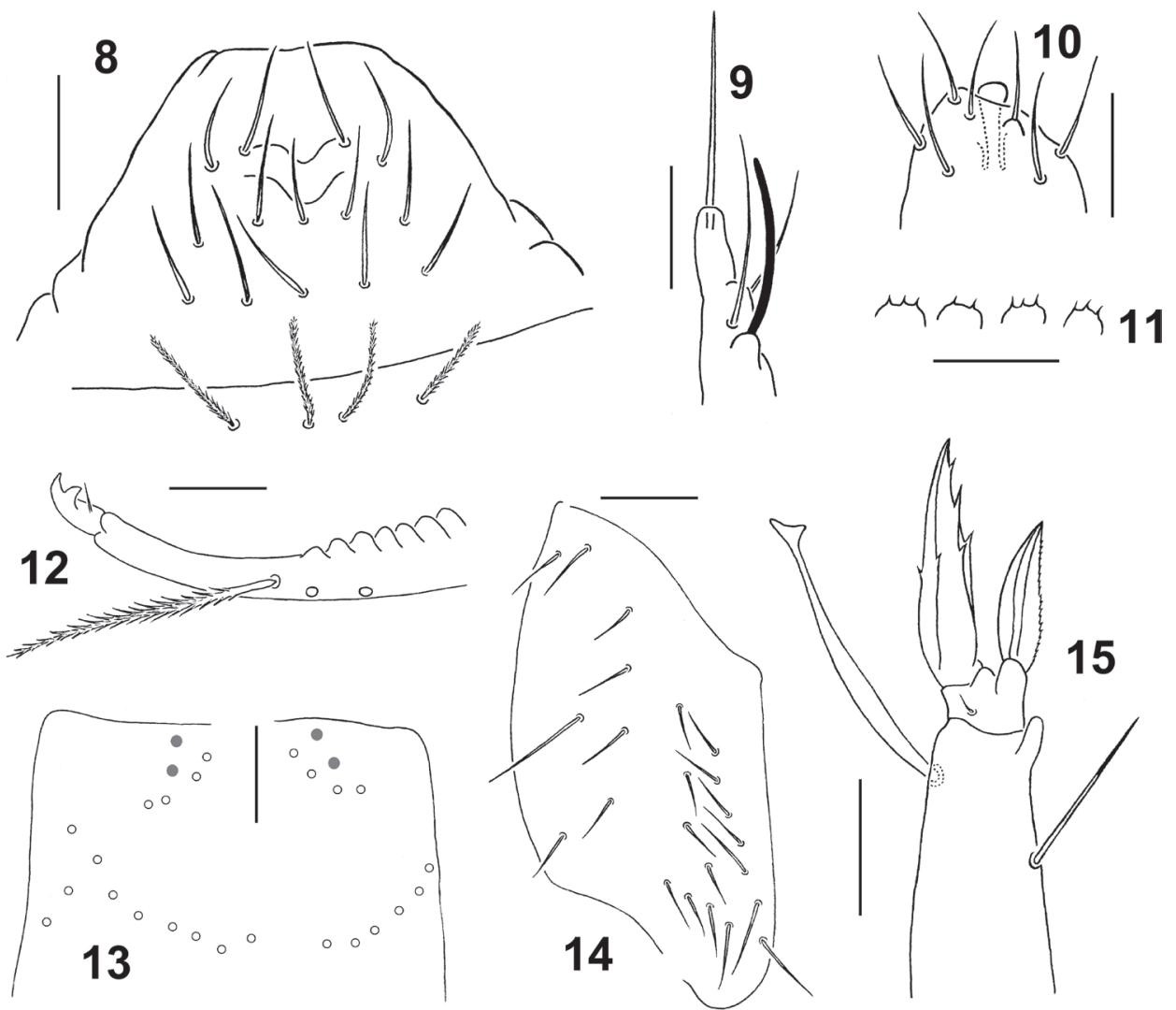

Figures 8-15. Entomobrya virginiae Arbea, sp. nov. 8 labrum 9 labial papilla E 10 tip of Ant IV I I labral papillae $\mathbf{I} \mathbf{2}$ tip of dens and mucro $\mathbf{3}$ manubrial plate (open circles = Mc; gray circles = pseudopores) $\mathbf{1} \mathbf{4}$ trochanteral organ $\mathbf{I} \mathbf{5}$ claw and empodium of leg III; Scale bars: $0.02 \mathrm{~mm}(\mathbf{8}, \mathbf{I} \mathbf{2}-\mathbf{I 5})$, $0.01 \mathrm{~mm}(\mathbf{9}-\mathrm{II})$.

Legs. Trochanteral organ with 15-16 smooth chaetae in V-shaped and 7-8 lateral smooth chaetae (Fig. 14). Tibiotarsus not subsegmented, without smooth chaetae, except for smooth terminal chaeta on legs III. Claw with four inner teeth: paired at $53-58 \%$ (one of them larger and forward), first unpaired at 70\% from basis, and the last one closer than 90\%; dorsal teeth at the level of lateral teeth (Fig. 15). Empodium lanceolate, with serrated external lamella in leg III. Tenent hair clavate, longer than claw.

Remarks. For the identification of the species of Entomobrya we must consider a combination of colour pattern and dorsal macrochaetotaxy. It has been shown that species with the same colour pattern can have a different chaetotaxy (Jordana and Baquero 2005). On the other hand, species with differences in color pattern can correspond with species-level genetic divergence without any obvious differences in chaetotaxy (Katz et al. 2015b).If the macrochaetotaxy of Th II/Abd II/Abd III is considered simultaneously, twelve species of the genus share a similar simplified formula for these tergites: 2-3/2-3/1-2-1 in E. atrocincta Schött, 1896, E. maroccana Baquero \& Jordana, 2008, E. melitensis Stach, 1963, E. numidica Baquero, Hamra-Kroua \& Jordana, 2009, E. vergarensis Baquero, Arbea \& Jordana, 
Table I. Measurements of E. virginiae sp. nov. (in micrometers), average from 16 specimens.

\begin{tabular}{lcccc}
\hline & Holotype & Mean & Min. & Max. \\
\hline Ant I & 129 & 131 & 87 & 179 \\
Ant II & 308 & 312 & 225 & 469 \\
Ant III & 326 & 317 & 230 & 437 \\
Ant IV & 313 & 319 & 253 & 1522 \\
Ant & 1076 & 1078 & 795 & 446 \\
Head & 377 & 344 & 267 & 3,81 \\
Ant/Head ratio & 2,85 & 3,13 & 2,54 & 322 \\
Th II & 230 & 216 & 161 & 184 \\
Th III & 170 & 144 & 92 & 175 \\
Abd I & 175 & 123 & 55 & 221 \\
Abd II & 170 & 161 & 92 & 184 \\
Abd III & 134 & 74 & 671 \\
Abd IV & 536 & 486 & 377 & 5,60 \\
Abd IV/III ratio & 333 & 2,80 & 138 \\
Abd V & 3,42 & 378 & 92 & 97 \\
Abd VI & 138 & 112 & 51 & 2323 \\
Body & 87 & 76 & 1353 & 483 \\
Manubrium & 2036 & 1795 & 285 & 561 \\
Dens & 368 & 347 & 354 & 86 \\
Claw & 469 & 430 & 58 & 58 \\
Empodium & 77 & 71 & 37 & 86 \\
Tenent hair & 47 & 47 & 63 & \\
\hline
\end{tabular}

2010, E. fainae Baquero \& Jordana, 2018 and E. benaventi Rueda \& Jordana, 2020; 2-4/23/1-2-1 in five species described by Baquero and Jordana (2018) from the Canary Islands, E. grimanesae, E. achuteygai, E. cf. quinquelineata, E. guayarminae and E. gazmirae; of these twelve species, only E. melitensis, E. vergarensis, E. fainae and the females of $E$. atrocincta sensu Katz et al., 2015a, and E. benaventi have a colour pattern similar to the new species; but the new species is the only one with Mc a5' on Th II in females. The colour pattern of the new species could also be considered similar to that of E. multifasciata, E. atteneri and females of $E$. nigrocincta, which have a different macrochaetotaxy formula for the Th II (Mc a5' present in females of the new species vs. absent in others) and Abd II tergites (2-2 in E. multifasciata, 2-4 in E. atteneri, 1-2 in E. nigrocincta vs. 2-3 in the new species). Table 2 shows the differences that separate these species from the $E$. virginiae sp. nov.

\section{Lepidocyrtus flexicollis Gisin, 1965}

New Sierra de Grazalema (Málaga) record.

Material studied. Cueva del Gato. 9-VIII-2018, 2 ex. in twilight and 11 ex. in dark zone; 16-VIII-2018, 4 ex. in twilight and 11 ex. in dark zone; 23-VIII-2018, 3 ex. in twilight zone; 30-VIII-2018, 2 ex. in dark zone; 16-IX-2018, 8 ex. in dark zone; 20IX-2018, 16 ex. in twilight zone; 4-X-2018, 25 ex. in twilight and 39 ex. in dark zone.

Known species from the Canary Islands and the southeastern part of the Iberian Peninsula. This troglophilous species is relatively common in subterranean habitats (Arbea 2013). 
Table 2. Differences of E. virginiae sp. nov. among the similar species of Entomobrya by colour pattern and/or macrochaetotaxy of Th II and Abd II-III tergites. The species share: Mc S'0 on H3 area of head absent; Th II with $2 \mathrm{Mc}$ on T1 area; Abd III with 1/1 Mc on A3/A5 areas; Abd IV without unpair chaetae on $\mathrm{A} 7$ and $\mathrm{A} 9$ areas and the trichobothrium at the level T2 and T4. $\mathrm{U}=$ unknown character. Differences with E. virginiae sp. nov. in bold. References: 1, Christiansen and Bellinger (1998); 2, Jordana (2012); 3, Katz et al. (2015a); 4, Baquero and Jordana (2018); 5, Rueda and Jordana (2020).

\begin{tabular}{|c|c|c|c|c|c|c|c|c|c|c|c|c|c|c|c|c|c|}
\hline & 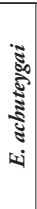 & 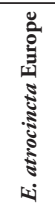 & 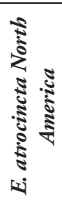 & 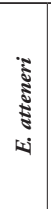 & 幽 & 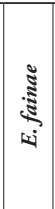 & 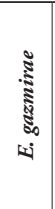 & 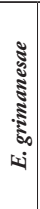 & 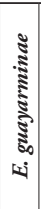 & 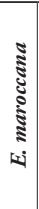 & 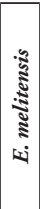 & 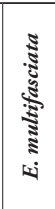 & 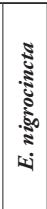 & 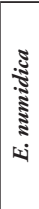 & 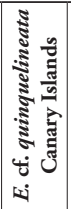 & 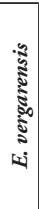 & 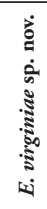 \\
\hline Ch.1 H1 (Head) An2-An3 & 3 & 2 & 3 & 3 & 3 & 3 & 3 & 3 & 3 & 3 & $\mathrm{U}$ & 3 & 3 & 3 & 3 & 3 & 3 \\
\hline Ch.2 H2 A5-A7 & 2 & 1 & $1(2)$ & $2-3$ & 1 & 1 & 2 & 1 & 1 & 1 & $\mathrm{U}$ & 1 & 1 & 1 & 1 & 3 & 2 \\
\hline Ch.3 H4 S1-S3-S4 & 3 & 3 & 3 & 3 & 3 & 3 & 3 & 3 & 3 & 2 & $\mathrm{U}$ & $3(2)$ & 2 & 3 & 3 & 3 & 3 \\
\hline Ch.4 H5 Ps2-Ps3-Ps5 & 2 & 2(3) & 2 & 2 & 2 & 2 & 2 & 2 & 2 & 2 & $\mathrm{U}$ & 2 & 2 & 3 & 2 & 3 & 2 \\
\hline $\begin{array}{l}\text { Ch. } 5 \text { Labral papillae: smooth papillae (1), with } \\
\text { some projections ( } 2 \text { ) }\end{array}$ & 2 & 1 & 2 & 2 & 2 & 1 & 1 & 2 & 1 & 1 & 2 & 2 & 2 & 2 & 2 & 2 & 2 \\
\hline $\begin{array}{l}\text { Ch.6 Length of lateral process subequal to labial } \\
\text { papilla E (1) or shorter than labial papilla E (2) }\end{array}$ & 2 & $\mathrm{U}$ & $\mathrm{U}$ & 1 & 1 & 1 & 2 & 1 & 1 & $\mathrm{U}$ & U & 1 & $\mathrm{U}$ & $\mathrm{U}$ & 2 & $\mathrm{U}$ & 1 \\
\hline Ch.7 eyes G\&H size $=\mathrm{E} \& \mathrm{~F}(1),<\mathrm{E} \& \mathrm{~F}(2)$ & 2 & 2 & 2 & 2 & 2 & 2 & 2 & 2 & 2 & 1 & 2 & 2 & 2 & 2 & 2 & 2 & 2 \\
\hline $\begin{array}{l}\text { Ch. } 8 \text { apical antennal retractile bulb absent ( } 0) \text {, } \\
\text { lobe simple (1), bilobed (2) }\end{array}$ & 2 & 1 & $1-2$ & 2 & 2 & 2 & $1(0)$ & 2 & 2 & 1 & 2 & $1-2$ & 2 & 2 & 2 & 2 & 1 \\
\hline Ch.9 T2 chaetae number a5, m4-m5 & 4 & 3 & 3 & 4 & 3 & 3 & 4 & 4 & 4 & 3 & 3 & 3 & 3 & 3 & 4 & 3 & $4(3)$ \\
\hline Ch.10 T2 chaeta a5' & 0 & 0 & 0 & 0 & 0 & 0 & 0 & 0 & 0 & 0 & 0 & 0 & 0 & 0 & 0 & 0 & $1(0)$ \\
\hline Ch.11 Claw internal teeth 3(3), 4(4) & 4 & 4 & 4 & 4 & 4 & 4 & 4 & 4 & 4 & 4 & 3 & 4 & 4 & 4 & 4 & 4 & 4 \\
\hline $\begin{array}{l}\text { Ch.12 Claw dorsal tooth absent (0), basal (1), } \\
\text { internal teeth level (2) }\end{array}$ & 1 & 2 & 2 & 1 & 1 & 2 & 1 & 2 & 2 & 2 & 0 & 1 & 2 & 1 & 1 & 2 & 2 \\
\hline Ch.13 A1 Abd II a2-a3 & 2 & 2 & $2(1)$ & 2 & 2 & 2 & 2 & 2 & 2 & 2 & 2 & 2 & 1 & 2 & 2 & 2 & 2 \\
\hline Ch.14 A2 Abd II m3 series chaetae number & 3 & 3 & 2(3) & 4 & 3 & 3 & 3 & 3 & 3 & 3 & 3 & $2-3$ & 2 & 3 & 3 & 3 & 3 \\
\hline Ch.15 A4 Abd III above $\mathrm{m} 2$ chaetae number & 2 & 2 & 2 & 2 & 2 & 2 & 2 & 2 & 2 & 2 & 2 & 2 & 1 & 2 & 2 & 2 & 2 \\
\hline Ch.16 A6 Abd IV A1-D1 chaetae number & 0 & 0 & 0 & 0 & 1 & 0 & 1 & 0 & 0 & 0 & 0 & 0 & 0 & 0 & 0 & 0 & 0 \\
\hline Ch.17 A7 Abd IV A2-E1 chaetae number & 4 & 4 & $1(4)$ & 4 & 3 & 3 & 4 & 2 & $\mathbf{0}$ & $\mathbf{0}$ & $\mathbf{0}$ & $2-3$ & 2 & 2 & $2(3)$ & 3 & $3-4$ \\
\hline Ch.18 A8 unpair chaeta A04 & 0 & 0 & 0 & 0 & 0 & 0 & 0 & 0 & 0 & 0 & 0 & 0 & 0 & 0 & 0 & 1 & 0 \\
\hline Ch.19 A8 Abd IV A4a-C2a chaetae number & 3 & 3 & 3 & 3 & 3 & 4 & 3 & 3 & 3 & 3 & 4 & 3 & 3 & 3 & $3-4$ & 5 & 3 \\
\hline Ch.20 A9 Abd IV A5-B5 chaetae number & 2 & 3 & 2 & 2 & 2 & 2 & 2 & 2 & 2 & 2 & 2 & 2 & 2 & 2 & 2 & 2 & 2 \\
\hline Ch.21 A10 Abd IV A6-B6 chaetae number & 2 & 3 & 2 & 2 & 2 & 2 & 2 & 2 & 2 & 2 & 2 & 2 & 2 & 2 & 2 & 2 & 2 \\
\hline Ch.22 Manubrial plate chaetae number & 5 & $3-4$ & $3-4$ & $4-6$ & $\mathrm{U}$ & $4-6$ & $6-7$ & 4 & 4 & $\mathrm{U}$ & 4 & 4 & 4 & 4 & $3-4$ & 4 & 4 \\
\hline $\begin{array}{l}\text { Ch.23 Sexual dimorphism in colour present (1) } \\
\text { or absent }(0)\end{array}$ & $\mathrm{U}$ & 0 & 1 & 0 & 1 & 0 & $\mathrm{U}$ & 0 & $\mathrm{U}$ & 0 & 0 & 0 & 1 & 0 & 0 & 0 & 0 \\
\hline $\begin{array}{l}\text { Number of differences in relation to } E \text {. virginiae } \\
\text { sp. nov. }\end{array}$ & 4 & 5 & 1 & 3 & 5 & 4 & 5 & 3 & 4 & 5 & 5 & 2 & 8 & 5 & 5 & 5 & - \\
\hline References & 4 & 2 & 1,3 & 4 & 5 & 4 & 4 & 4 & 4 & 2 & 2 & 2,4 & 2,4 & 2 & 4 & 2 & \\
\hline
\end{tabular}

\section{Family Sminthurididae Börner, 1906}

\section{Sphaeridia pumilis (Krausbauer, 1898)}

New Sierra de Grazalema (Málaga) record.

Material studied. Cueva del Gato. 9-VIII-2018, 21 ex. in twilight zone; 16-IX-2018, 23 ex. in dark zone; 20-IX-2018, 6 ex. in twilight zone; 4-X-2018, 5 ex. in twilight and 11 ex. in dark zone. 

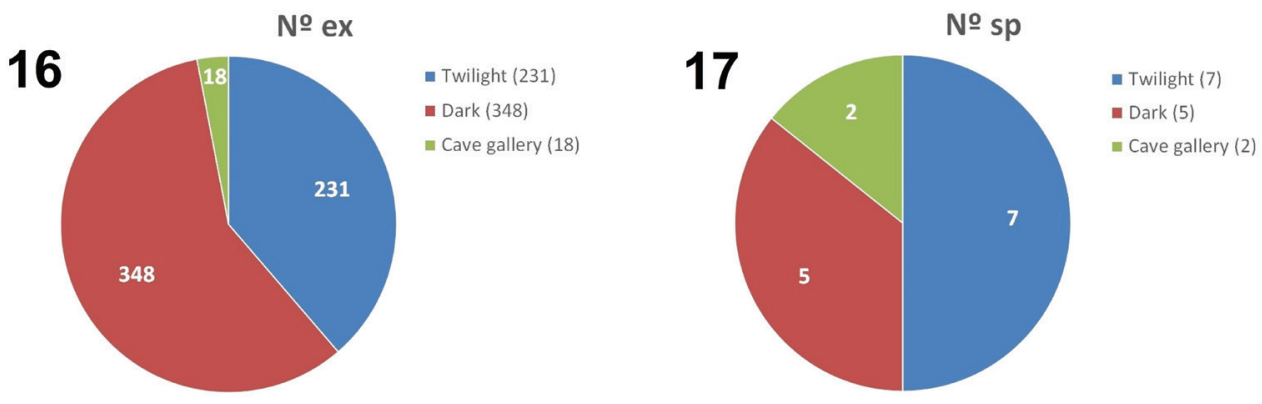

Total specimens

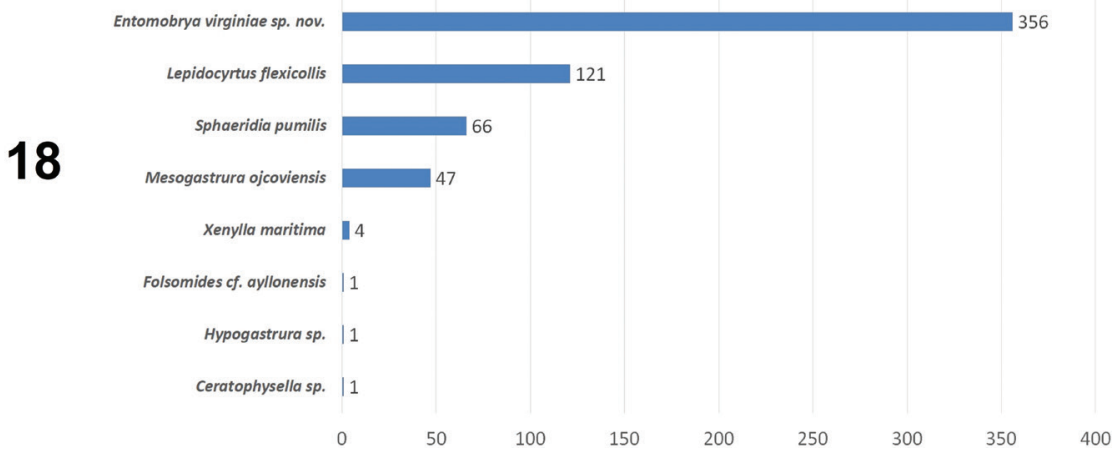

Figures 16-18. Diversity of Collembola in Gato cave 16 total number of Collembola specimens recorded $\mathbf{I} \mathbf{7}$ number of Collembola taxa recorded $\mathbf{I} 8$ abundance of eight species of Collembola collected.

This is a cosmopolitan species widely distributed in Europe and North America. Occurs on the surface and in upper layers of different moist soils and in their low vegetation. Occasionally appears in caves from Spain (Jordana and Beruete 1983) and other European caves.

\section{Discussion}

The number of springtails collected is higher in dark zone (58\% of all Collembola collected), but the twilight zone proved to be the most richness - of the eight species recorded in this study, we recorded seven in the twilight and only five in the dark zone (Figs 16, 17). The troglophilous species Ceratophysella sp., Hypogastrura sp. and Xenylla maritima were recorded from only the twilight zone at the cave entrance (Fig. 1).

Four of the eight species were represented by only one to four specimens (Fig. 18). The high number of individuals is attributable to two species, Entomobrya virginiae sp. nov., for which 356 specimens (59.6\% of all springtail specimens collected during this study) were collected from all zones of the cave, and Lepidocyrtus flexicollis with 121 specimens. The next two most abundant species were Sphaeridia pumilis, with 66 specimens (11\% of all Collembola collected), and Mesogastrura ojcoviensis, with 47 specimens ( $7.9 \%$ of all Collembola collected). 


\section{Acknowledgements}

To thank the Department of Zoology of the University of Seville for their unconditional and essential support for the surveys and the authorities responsible for the "Sierra de Grazalema Natural Park", as well as the "Consejería de Agricultura, Ganadería, Pesca y Desarrollo Sostenible, Junta de Andalucía" that provided the authorizations and permits for the execution of the work. Also thank our friend Toni Pérez Fernández for directing us to the underground world. The authors also would like to thank Enrique Baquero and Aron Katz who provided excellent comments and suggestions that improved this manuscript.

\section{References}

Arbea JI (2012) Review of the genus Onychiurus Gervais, 1841 (Collembola: Onychiuridae) with description of a new cave species from Southern Spain. Zootaxa 3564: 33-45. https:// doi.org/10.11646/zootaxa.3564.1.3

Arbea JI (2013) Los Colémbolos (Hexapoda, Collembola) subterráneos de Jaén. In: Pérez Fernández T, Pérez Ruiz A (Eds) Los invertebrados de hábitats subterráneos de Jaén, Grupo de Espeleología de Villacarrillo (G.E.V.) Jaén, 104-114.

Arbea JI, Baena M (2003) Colémbolos cavernícolas de Andalucía (Insecta: Collembola). Zoología Baetica 13/14: 71-84.

Arbea JI, Pérez Fernández T, Carrasco P (2011) Deuteraphorura cebennaria (Gisin, 1956) primera cita para la fauna de la Península Ibérica (Collembola, Onychiuridae). Boletín de la Sociedad Entomológica Aragonesa 48: 351-357.

Baquero E, Jordana R (2018) Entomobrya (Collembola, Entomobryidae) for the Canary Islands. Zootaxa 4461(2): 151-195. https://doi.org/10.11646/zootaxa.4461.2.1

Barrientos JA, García-López V, Soria FJ (2019) Arañas (Arachnida, Araneae) del Complejo Hundidero-Gato (Málaga, España). Revista Ibérica de Aracnología 35: 3-8.

Belda-García IM, Barranco-Vega P, García-Mayoral J (2014) Protección de la fauna invertebrada cavernícola en Andalucía. Iberoamérica Subterránea: 419-429.

Boeters HD (1980) Unbekannte westeuropäische Prosobranchia, 3. Basteria 44: 61-64.

Christiansen K, Bellinger P (1998) The Collembola of North America north of the Rio Grande; A taxonomic analysis ( $2^{\text {nd }}$ Edn.). Grinnell College, Grinnell.

Deeleman-Reinhold CL (1984) Dutch biological and speleological exploration in Algeria. 3. Sur quelques Linyphiidae cavernicoles de la région méditerranéenne occidentale (Araneae). Revue Arachnologique 6: 37-48.

Domingo-Quero T, Alonso-Zarazaga MÁ (2010) Soil and litter sampling, including MSS. Abc Taxa 8(1): 173-212.

Fjellberg A (1993) Revision of European and North African Folsomides Stach with special emphasis on the Canarian fauna (Collembola: Isotomidae). Entomologica scandinavica 23: 453-473. https://doi.org/10.1163/187631292X00245

García-López V, Soria FJ, García-Algaba FJ, Pérez-Fernández T (2020) Los invertebrados del sistema Hundidero-Gato (Montejaque-Benaoján, Málaga). Catálogo provisional. Gota a Gota (20): 73-79. 
Guerrero Sánchez M (2015) El Sistema Hundidero-Gato. Estudio, Descripción, Historia. Málaga, 175 pp.

Hernando C, García-López V (2016) Un nuevo Phloeocharis Mannerheim, 1830 encontrado en el medio subterráneo del sur de España (Coleoptera: Staphylinidae: Phloeocharinae). Heteropterus Revista de Entomología 16(2): 125-131.

Jordana R (2012) Capbryinae and Entomobryini. In: Dunger W, Burkhardt U (Eds) Synopses on Palearctic Collembola. Soil Organisms 84(1): 1-391.

Jordana R, Arbea J, Simón JC, Luciáñez MJ (1997) Collembola, Poduromorpha. In: Ramos MA et al. (Eds) Fauna Ibérica (Vol. 8). Museo Nacional de Ciencias Naturales, CSIC, Madrid, 807 pp.

Jordana R, Baquero E (2005) A proposal of characters for taxonomic identification of Entomobrya species (Collembola, Entomobryomorpha), with description of a new species. Abhandlungen und Berichte des Naturkundemuseums Görlitz 76(2): 117-134.

Jordana R, Beruete E (1983) Cavernicolous Collembola from Karst Caves in the West of Navarra (Spain). Bulletin de la Société entomologique suisse 56(3-4): 303-315.

Katz AD, Giordano R, Soto-Adames F (2015a) Taxonomic review and phylogenetic analysis of fifteen North American Entomobrya (Collembola, Entomobryidae), including four new species. ZooKeys 525: 1-75.

Katz AD, Giordano R, Soto-Adames FN (2015b) Operational criteria for cryptic species delimitation when evidence is limited, as exemplified by North American Entomobrya (Collembola: Entomobryidae). Zoological Journal of the Linnean Society 173(4): 810-840. https://doi.org/10.1111/zoj.12220

Notenboom J (1987) Species of the genus Pseudoniphargus Chevreux, 1901 (Amphipoda) from the Betic Cordillera of southern Spain. Bijdragen tot de Dierkunde 57: 87-150. https:// doi.org/10.1163/26660644-05701008

Rueda J, Jordana R (2020) Checklist of Collembola (Hexapoda: Entognatha) from "malladas" of the Devesa and Racó de l'Olla (Albufera Natural Park, Valencia, Spain) with a description of a sp. nov. Limnetica 39(1): 93-111.

Simón JC, Luciáńez MJ (1990) Estudio colembológico de diferentes pastizales de la Sierra de Ayllón, con descripción de dos nuevas especies (Insecta, Collembola). Eos 66(1): 67-77.

Szeptycki A (1979) Chaetotaxy of the Entomobryidae and its Phylogenetical Significance. Morphosystematic studies on Collembola. IV. Polska Akademia Nauk, Kraków, 218 pp.

Thibaud J-M, Schulz HJ, Gama MM da (2004) Synopses on Palaearctic Collembola: Hypogastruridae. Abhhandlungen und Berichte des Naturkundemuseums Görlitz 75(2): 1-287. 